School of Psychology and Neuroscience, University of St. Andrews

Cite this as: BMJ 2021;375:n3150 http://dx.doi.org/10.1136/bmj.n3150 Published: 24 December 2021

\title{
It is wrong to claim that the public won't follow covid rules just because the government don't
}

Stephen Reicher professor of psychology

As cases of omicron surge and as countries across Europe-and also within the UK-introduce new measures to limit the spread, England remains an outlier by refusing to do any more than to advise people to "exercise caution." One of the reasons used to explain this stance is that the public simply would not tolerate the reintroduction of covid measures-an argument endorsed by some of the government's opponents such as Tony Blair who was quoted as saying "the only intervention that would really work against Omicron (is) a full lockdown, and... the public would not tolerate that."

To add farce to the tragedy, a narrative has developed that explains public reluctance to abide by covid measures through the government's own failures to do so. Constant stories about Westminster parties have led people to think "why should I follow rules that are flouted by those who set them?" Indeed, one poll found this as the main reason respondents gave for saying that they would not follow household mixing regulations if these were introduced over Christmas (albeit only by $10 \%$ of them.) ${ }^{1}$

But this narrative is doubly wrong and dangerously so. It misconstrues the impact of government misdemeanours, it misrepresents the nature of public behaviour and, if it overstates the toxicity of the present, it is in danger of creating a more toxic future. Let us address each of those in turn.

First, it is undeniable that Westminster rule breaking has greatly undermined trust in and approval of our rulers. The numbers who think Boris Johnson, the UK prime minister, is doing badly have risen from $26 \%$ to $71 \%$ since the early summer; the numbers approving of the government record have almost halved (from $37 \%$ to $20 \%$ ) in the same period, and the numbers who trust the Conservative Party have fallen as low as $10 \%$ (from $16 \%$ a couple of months back). ${ }^{2-4}$

Loss of trust is serious in a number of ways, not least in terms of loss of influence. But, critically, loss of trust does not map directly on the loss of adherence. Rather, it has a number of sometimes contradictory effects. Thus, on the one hand, there is no doubt that among people who never supported the rules, it provides a warrant (excuse) to break them. This was widely reported in the aftermath of the Cummings affair. ${ }^{5}$ On the other hand, overall, those who were angry at Cummings increased their adherence in order to show that we, unlike "they" (the government) don't think it is OK to bend the rules. ${ }^{6}$

In short, as government behaviour leads to a sense of "us" and "them," the government becomes an outgroup against whom we contrast ourselves, rather than an ingroup who we use as a guide. ${ }^{7}$ We adhere despite and not because of them. While this is certainly not a desirable situation (in the midst of a national crisis, clear and trusted leadership with the moral authority to guide us through difficult times is clearly desirable), it is important not to overstate the implications. After all, loss of government authority doesn't mean loss of authority overall. While trust in the former may be increasingly low, trust in science and scientists has risen globally during the pandemic. ${ }^{8}$ This was corroborated by a December 2021 MORI poll showing that $84 \%$ of people trust scientists, while the figures for doctors and nurses were, respectively, 91\% and 94\%. ${ }^{9}$ While there is considerable controversy as to whether the government is following the science it does seem that the public are listening.

This sense is reinforced when we turn to our second issue: are the public following present covid regulations and would they observe new measures? It is certainly true that people are sick and tired of covid measures, that they have been suffering from them, and that no one would welcome any further restrictions. But this is very different from saying that they will ignore them. Indeed, research from early 2020 shows that at least half of the population were suffering significantly from restrictions, but still less than $10 \%$ were resisting. ${ }^{10}$

Of course, one could argue that after two years, things are very different and people have given up. But that isn't what the evidence suggests. Data on our behaviour shows generally high levels of adherence and that adherence is increasing as people see the risk from covid increasing-as I suggested above, people not only trust the scientists and health professionals, but are responding to the scientific evidence. Thus, we are wearing masks more and mixing less-and those who mix more aren't doing so through partying, but through going to work. ${ }^{11}$ What is more, as evidence (and perceptions) of risk increases, so behaviour changes accordingly. This is reflected in three YouGov polls over 10 days from early to mid December which show that the percentage who had changed their Christmas plans rose from $17 \%$ to $31 \%$ (and $45 \%$ in London where Omicron risks are particularly high)-with many more still considering a change. ${ }^{12} 13$

When we turn from what people are doing now to what they think should be done next we find that, as throughout the pandemic, they are well ahead of the government and well aligned with the scientific advice coming from SAGE and others. For instance, even before omicron emerged, the public was well aligned with the SAGE call for "low cost interventions" (such as masks and working from home) to reduce infections. ${ }^{14}$ Notably, over 
three-quarters of people supported mandatory mask wearing on public transport $(81 \%)$ and in shops $(76 \%)$. They also supported social distancing and even closing nightclubs was supported by more than opposed it. ${ }^{15}$

More recent evidence tells a mixed story about what people would support. A Savanta Comres poll shows clear support for some restrictions on both public activities (e.g. closing nightclubs and mass events) and domestic activities (reimposing a "rule of 6" is endorsed by $55 \%$ to $28 \%$ ). ${ }^{16}$ It also shows support for a full two week lockdown (by $51 \%$ to $32 \%$ ) with support even higher in London (58\%). Other polls still show more people supporting closing nightclubs and reintroducing the domestic "rule of 6" than not, but with a narrower split and with almost a dead heat between those favouring and opposing an overall "lockdown." 1718 Despite these differences, none of the evidence supports the narrative that people are becoming ever more averse to new measures. Quite the opposite: they are hardening their support as evidence of risk emerges and in locations where risk is highest. The only uncertainty is just how far this support has hardened.

What is more, when asked the slightly different question of whether you would follow (as opposed to support) tougher regulations, the result was much clearer. $74 \%$ said yes. This compares to the $85 \%$ who, despite fears of widespread non-compliance, stuck to the last-minute regulations for Christmas 2020. ${ }^{19}$ Whether people support regulations before they are brought in and whether they will comply with them afterwards are two very different things. Once we take this into account, the notion that new measures are pointless because the public won't wear them becomes even less tenable.

There is one further point that needs consideration. It isn't only that policy support differs from policy compliance, but also that support itself is altered by the policy context. At one level it is remarkable that half of the population support full lockdown and many more support specific restrictions when we have a government who are loudly messaging that there is no clear evidence of risk and no justification for any policy changes. Equally, they are refusing to reinstate a furlough scheme and the other forms of support that are necessary if individuals and businesses are to be able to withstand the consequences of such measures. Given that clear information and adequate support are critical determinants of behaviour change, we could reasonably expect a considerable increase in support for measures if the nature of the risk and the rationale for them was made clear, and if any restrictions are accompanied by commensurate support packages. ${ }^{20}$

To summarise then, it is wrong for critics of the government to conclude that official misbehaviour inevitably undermines compliance with covid rules, and it is wrong for the government to excuse their inaction as resulting from public non-compliance. The evidence supports neither. People generally want more action, the majority will abide by new regulations and they would do so even more with a united lead from science, health, and government. This is what I mean when I say that the "partygate" narrative is doubly wrong. But what about my additional claim that it is dangerously wrong?

It is a simple point that many have made since the start of the pandemic. Norms matter. ${ }^{21}$ What we think others are doing often trumps what we think ourselves in determining behaviour. For what is the point of adhering to covid restrictions if no one else is doing so. Covid will spread whatever you do, so you might as well be at the party. The growing assumption among government critics and government supporters, in the liberal and conservative media alike, that everyone is giving up is in danger of making everyone give up. That is why it is so important to rebut it in the strongest possible terms.

Competing interests: Competing interests: SR participates in the UK's Scientific Advisory Group for Emergencies and/or its subgroups and in Independent SAGE. SR participates in the advisory group to the Scottish chief medical officer.

Provenance and peer review: commissioned, not peer reviewed

YouGov. One in ten would not follow new household mixing rule https://yougov.co.uk/topics/health/articles-reports/2021/12/10/one-ten-would-not-follow-new-household-mixing-rule

2 YouGov. Boris Johnson approval rating https://yougov.co.uk/topics/politics/trackers/boris-johnsonapproval-rating

YouGov. Government approval. https://yougov.co.uk/topics/politics/trackers/government-approval YouGov. Is the Conservative party trustworthy or untrustworthy? https://yougov.co.uk/topics/politics/trackers/is-the-conservative-trustworthy-or-untrustworthy?utm_source=twitter\&utm_medium=website_tracker\&utm_campaign=are_cons_trustworthy

The Guardian. Lockdown violators using Cummings excuse say police. May 2020.

https://www.theguardian.com/uk-news/2020/may/27/lockdown-violators-using-cummings-asexcuse-say-police

6 LSE. Public compliance covid-19 https://blogs.lse.ac.uk/politicsandpolicy/public-compliancecovid19-june/

Tajfel H. Differentiation Between Social Groups. Academic Press, 1978

8 Wellcome. Public trust in scientists rose during covid-19 pandemic. https://wellcome.org/news/public-trust-scientists-rose-during-covid-19-pandemic

9 IPSOS MORI. Trust in police drops second year in a row. https://www.ipsos.com/ipsos-mori/enuk/ipsos-mori-veracity-index-trust-police-drops-second-year-row

10 King's College London. Three ways people are reacting to coronavirus. https://www.kcl.ac.uk/threeways-people-are-reacting-to-coronavirus-accepting-suffering-and-resisting

11 Comix report survey Week 89. https://cmmid. github.io/topics/covid19/reports/comix/CoMix\%20Weekly\%20Report\%2089.pdf

12 YouGov. Have you cancelled or postponed any plans over the next couple of weeks, due to concerns about Covid-19 and the new variant? https://yougov.co.uk/topics/health/survev-results/daily/2021/12/13/93212/2?utm_source=twitter\&utm_medium=daily_questions\&utm_campaign=question_2

13 YouGov. How many Britons Christmas plans have had to change https://yougov.co.uk/topics/lifestyle/articles-reports/2021/12/20/how-many-britons-christmas-plans-have-had-change-

14 SAGE minutes. 9 September 2021 https://assets.publishing.service.gov.uk/government/uploads/system/uploads/attachment_data/file/1017296/S1360_SAGE_95_minutes.pdf

15 YouGov. Strong support in England for return of mask wearing. https://yougov.co.uk/topics/politics/articles-reports/2021/10/26/strong-support-england-return-mask-wearing-and-soc

16 ComResGlobal. Lockdown snap poll. December 2021. https://comresglobal.com/polls/lockdownsnap-poll-december-2021

17 YouGov. People in England remain opposed to a total ban on indoor socialising. https://yougov.co.uk/topics/politics/articles-reports/2021/12/14/people-england-remain-opposed total-ban-indoor-soc

18 News I. Three quarters of Brits would comply with Christmas ban on household mixing. https://inews.co.uk/news/politics/covid-poll-three-quarters-of-brits-would-comply-with-christmasban-on-household-mixing-1347703

19 Daily Mail. 85 percent of people complied with Christmas lockdown rules. https://www.daily mail.co.uk/news/article-9089553/85-cent-people-complied-Christmas-lockdown-rules-pollshows.html

20 Michie S, van Stralen MM, West R. The behaviour change wheel: a new method for characterising and designing behaviour change interventions. Implement Sci 2011;6:42. doi: 10.1186/1748-5908-6-42 pmid: 21513547

21 Neville FG, Templeton A, Smith JR, Louis WR. Social norms, social identities and the COVID-19 pandemic: Theory and recommendations. Soc Personal Psychol Compass 2021;15:e12596. doi: $10.1111 /$ spc3.12596 pmid: 34230834 